\title{
Competência em Medicina Física e Reabilitação
}

\author{
Linamara Rizzo Battistella*
}

Quando pensamos em Medicina Física e Reabilitação, imediatamente associamos a fisiologia e patologia do movimento. $\mathrm{O}$ ato motor e todas as suas implicações é objeto de estudo do médico fisiatra. Quando falamos em patologia do ato motor compreendemos inúmeras alterações das mais variadas etiologias que podem ser originárias da mais diversas causas, desde psíquicas até traumáticas, passando por enfermidades agudas, doenças crônicas degenerativas, e causas genéticas.

Então basicamente, estudamos a função sobretudo do movimento, e a partir de inúmeras causas, os efeitos deletéricos, que se manifestam através de mecanismos neuromusculares, que em última análise resultam numa perda da qualidade, ou até na incapacidade quanto a movimentação, função nobre que garante a vida socialmente produtiva e a independência do ser humano. Para exemplificar a patologia do movimento, é preciso lembrar que alterações da função do movimento podem ser vistas em doenças neuromusculares, a ausência do movimento em doenças oesteomioarticulares que cursem com dor incapacitante e nas lesões neurológicas como é o caso das Paraplegias e Tetraplegias. A falta de um seguimento ou de um membro pode originar uma incapacidade também do movimento, falta de segmento que, causado por defeitos congênitos como má formação ou amputações tramática ou degenerativa terão por si só expressões clínicas diferentes como repercussões funcionais de diferentes magnitudes. A dor por si só é um fenômeno importante nas alterações do movimento.

A dor incapacitante pode ter como origem distúrbios psicoafetivos, esforços de repetição ou micro-traumas, traumas agudos e doenças degenerativas. O paciente com lesão osteomioarticular pode não ter uma incapacidade funcional pela lesão, no entanto ele pode ter uma dor que determine uma incapacidade. Então o efeito das inúmeras causas que geram alterações patológicas do movimento podem didaticamente se-

\footnotetext{
Médica fisiatra, Doutora pela Universidade de São Paulo, Livre-Docente em Fisiatria pela UNI-RIO. Diretora Científica da APM - Biênio 93/95 e Diretora da Divisão de Medicina de Reabilitação do HC-FMUSP.
} 
rem divididas em alteração da função dos movimentos normais, falta do segmento efetor, a dor e as incapacidades funcionais que determinam alterações do movimento. A partir da determinação das disfunções e das alterações do movimento devemos propor a terapêutica. $\mathrm{O}$ tratamento deverá estar sempre embasado no diagnóstico da incapacidade e no prognóstico funcional desta patologia.

Alguns dados históricos da Medicina Física e Reabilitação, uma retrospectiva histórica feita nos Estados Unidos na década de $80^{(3)}$, mostra que essa especialidade se originou na década de 20 . No entanto foi durante a década de 30 que realmente ela atraiu um grupo de especialistas que a partir do estudo e da determinação das bases biológicas dos agentes físicos estabeleceu uma nova abordagem terapêutica.

Em quase todo o mundo, especialmente durante a guerra, sentiu-se a necessidade da formação de maior número de especialistas ${ }^{(1)}$. Na realidade a história da Medicina Física e Reabilitação está atrelada a peculiaridades da história e do desenvolvimento de cada país. No Brasil a poliomielite esteve sempre como a mais importante causa do desenvolvimento desta especialidade.

Todos os organismos nacionais e internacionais que congregam estes especialistas tiveram a preocupação de definir uma abordagem própria deste médico e ninguém mais tem dúvida do instrumental e do arsenal terapêutico utilizado pelo médico fisiatra ${ }^{(1)}$. Sem esquecer as bases da medicina interna o fisiatra vai buscar também recursos físicos que possam proporcionar melhores condições terapêuticas aos seus pacientes, e ampliar os meios diagnósticos.

$\mathrm{Na}$ realidade quando falamos em Medicina Física e Reabilitação, temos por um lado o consenso sobre a abordagem que este profissional tem em relação ao seu enfermo que pode ter uma lesão potencialmente incapacitante ou uma incapacidade instalada, por outro lado, há necessidade de prevenir, tratar ou limitar todos os fenômenos que intervém na função motora, recuperando o movimento para sua concreta aplicação nas atividades funcionais da vida diária, na locomoção, na profissionalização e no desempenho social deste paciente.

Alguns especialistas de ensino médico costumam defender a idéia de que uma especialidade deve ser caracterizada pelo grau de mortalidade e morbidade que oferece. Nos parece que este seja um critério que deva ser considerado. Na realidade quando observamos os poucos dados existentes referentes a epidemiologia da incapacidade nos defrontamos com um número realmente assustador.

A Organização Mundial da Saúde (OMS) estima que em torno de $10 \%$ do total da população de um país em tempo de paz, é portadora de algum tipo de deficiência e destes aproximadamente $4 \%$ são portadores de deficiências físicas incapacitantes que é a área de atuação preponderante desse especialista $^{(1)}$.

Do ponto de vista da morbidade, os estudiosos americanos asseguram que cerca de 10 milhões de pessoas são beneficiários de recursos previdenciários o que significa uma compensação efetiva em dinheiro e a utilização de recursos médicos assistenciais a nível hospitalar e domiciliar.

Em 1982, nos Estados Unidos, a compensação trabalhista teve um custo aproximado de 13 bilhões de dólares e o seguro social 23,1 bilhões de doláres o que pode traduzir o alto custo social e econômico da morbidade nas pessoas portadoras de deficiência ${ }^{(2)}$.

Kottke $^{(3)}$ afirma que 3 a $5 \%$ da população necessita de serviços de Reabilitação em algum período de sua vida.

Quando lembramos a abordagem técnicocientífica da especialidade e raciocinamos sobre competência em Medicina Física e Reabilitação, é preciso refletir sobre áreas da Medicina que consolidaram a sua prática a partir das peculiaridades funcionais da sua clientela. Para lembrar alguns exemplos:

- "A criança não é um adulto em miniatura". Sobre esta assertiva desenvolveu-se uma área do conhecimento que, integrando as especialidades clínicas privilegiou uma faixa etária que realmente tem limites biológicos distintos do adulto e onde as intervenções devem necessariamente respeitar o processo de crescimento e desenvolvimento.

- A Geriatria surgiu a partir da verificação que o processo de envelhecimento também tem características que devem ser respeitadas. A clínica do idoso é na atualidade uma área de grandes investimentos a nível de pesquisa e ensino por se tratar de procedimento que objetiva prevenir a deterioração da qualidade de vida.

A partir do entendimento sobre as necessidades do infante e do geronte é coerente admitir que o incapacitado por suas limitações funcionais definitivas, pela alteração dos seus limites biológicos e fisiológicos, pela globalidade dos efeitos deletérios resultantes da limitação e incapacidade do movimento, necessite de cuidados clínicos-assistenciais 
diferenciados o que resulta na necessidade de assistência do Fisiatra, o especialista que desenvolve a clínica do incapacitado.

Manifestação de várias magnitudes e comprometendo diferentes sistemas do corpo humano podem coexistir com incapacidades transitórias ou definitivas. Alguns exemplos podem facilitar a compreensão:

- A dor crônica de origem vertebral freqüentemente está associada a vícios posturais decorrentes da atitude profissional ou de erros inatos do desenvolvimento. Estes quadros podem gerar depressão reativa, e/ ou a falta de uso pode acelerar, sobretudo nas mulheres, a osteoporose, apenas para citar alguns distúrbios correlatos.

- A lesão medular pelas alterações tróficas de pele e a falta de estímulo vásculo-nervoso por alteração neurológica pode levar a escaras. O imobilismo, a calcificação para-articular, disfunção vesicouretral e cardiopulmonar são fatos que exigem atenção e acompanhamento especializado.

A Medicina de Reabilitação foi sabidamente a primeira área do conhecimento médico a preocupar-se com a qualidade de vida e a desenvolver estratégias para prevenir e limitar as incapacidades e a deterioração do ser humano.

É preciso reconhecer que as competências em Fisiatria estão necessariamente atreladas às competências em clínica médica voltadas para o enfermo incapacitado de forma transitória ou definitiva.

Não é uma tarefa simples, dentro de um dinamismo assegurado pelas mudanças de conceitos, definir e limitar as especialidades médicas. O Professor Clementino Fraga Filho ${ }^{(2)}$, quando fala do ensino da clínica médica, se reporta a estudos, conferências e debates que desde 1961, são levados a efeito na tentativa de definir o ensino e a competência em clínica médica. É o clínico do incapacitado que deve hierarquizar procedimentos, instrumentalizar os outros especialistas na abordagem deste paciente e contemplar a dinâmica de uma equipe capaz de oferecer a este paciente os cuidados necessários do ponto de vista da fase aguda da instalação da lesão, com a proposta de se prevenir seqüelas e limitar as incapacidades decorrentes da própria doença, e de acompanhar este paciente até a fase de alta hospitalar para avaliar a necessidade e a oportunidade do encaminhamento para o centro de Reabilitação.

A correlação que efetivamente existe entre a Clínica Médica e a Medicina Física e Reabilitação ou Fisiatria - nos permite referendar alguns dos princípios ditados por vários organismos sobre competências em clínica médica, extrapolando estes ditames para a Medicina de Reabilitação ${ }^{(2)}$.

1) conhecimentos dos fundamentos científicos da clínica, tendo em conta que a Medicina atual e ciência, em suas bases e na metodologia do en$\operatorname{sino}^{(2)}$;

2) aptidão para coleta de dados, com vistas a formulação de hipóteses diagnósticas: desenvolver a capacidade de colher elementos pela anamnese e pelo exame físico, e de raciocinar sobre esses elementos ${ }^{(2)}$, para encaminhar a solução do problema do diagnóstico e do prognóstico funcional;

3) juízo crítico na seleção dos exames complementares e capacidade de interpretação dos resultados. É indispensável, diante do número imenso de exames disponíveis, alguns de alta complexidade e elevado custo, que sua solicitação seja feita com discernimento ${ }^{(2)}$;

4) aptidão para aplicar métodos da epidemiologia no estudo de problemas clínicas: freqüência das doenças, casualidade, fatores de risco, medidas clínicas, necessidade de levar em conta custo/benefício nas decisões quanto ao diagnóstico funcional e à terapêutica reabilitativa;

5) juízo da oportunidade de encaminhamento a outros especialistas. A boa formação geral do Fisiatra permitirá que resolva a maioria dos problemas, sem a necessidade de referir o pacien$\mathrm{te}^{(11,2)}$.

6) compreensão integral do paciente e de suas inter-relações com a família e o meio ambiente, traduzindo a necessidade de avaliação global, nos aspectos psicossomáticos e na influência de fatores sociais, ocupacionais e ambientais na evolução das doenças;

7) aptidão para realizar procedimentos invasivos mais comuns, tais como punções de veias, artrocentese, cateterismo vesical, desbridamento de escara, bloqueios nervosos.

8) preparo para o relacionamento como o paciente e sua família em termos humanitários e éticos. O ensino da ética e da bioética, decorrente dos progressos científicos e tecnológicos é um dos aspectos mais importantes e, no entanto, mais descuidados da educação médica atual ${ }^{(2)}$;

9) aptidão para o trabalho em equipe. O treinamento nesse sentido deve iniciar-se cedo, na fase de graduação, para que o estudante crie hábitos de trabalho em conjunto e de respeito aos outros profissionais de saúde ${ }^{(2)}$; 
10) conhecimento dos problemas de saúde da comunidade e consciência do compromisso social do médico ${ }^{(2)}$. Esse atributo reflete a participação do Fisiatra no que se considera, hoje, fundamental, ou seja, a responsabilidade da escola médica em face da sociedade e a concientização da comunidade em geral sobre as reais possibilidades de pessoa portadora de deficiência;

14) treinamento para atividades diagnósticas específicas que envolvam avaliação eletroneurofisiológica dos músculos e nervos (eletrodiagnóstico clássico, eletroneuromiografia e potencial provocado) avaliação dinâmica do movimento e dinamometria mioarticular.

Competências em Medicina Física poderiam ser também avaliadas a partir do que se encontra nos livros textos nacionais e estrangeiros. A despeito de pequenas variações e maior interesse em determinados assuntos, todos os livros destas áreas contemplam estes temários:

1 - Medicamentos freqüentes em Reabilitação;

2 - Modalidades terapêuticas - Agentes físicos;

3 - Exercícios: princípios, metodologia e prescrição, Exercício e repouso;

4 - Eletrodiagnóstico, Eletromiografia Potencial provocado;

5 - Fibromialgia e dor miofascial;

6 - Dor Crônica;

7 - Orteses, Próteses e auxiliares para locomoção;

8 - Lesão Medular;

9 - Hemiplegia;

10 - Paralesia Cerebral;

11 - Poliomelite;

12 - Sd do imobilismo;

13 - Reabilitação Profissional;

14 - Terapia da Comunicação;

15 - Atividades de vida diária;

16 - Análise da marcha.

A partir destes dados, fica fácil inclusive verificar que nos livros textos de especialidades de domínio conexo não se encontram elencados estes assuntos, pois já está bem definido o que é competência do médico fisiatra.
Por último, os procedimentos que envolvem uma especialidade devem ser conceituados e definidos enquanto recursos diagnósticos ou terapêuticos e deve ser entendido que o recurso terapêtico por si só não define uma especialidade, porém, deve, por força de segurança do próprio paciente, ser aplicado exclusivamente pelo especialista ou por ele supervisionado, uma vez que a terapêtica deve pressupor o conhecimento da patologia e dos distúrbios associados, dos efeitos, das reações colaterais e dos limites de sua aplicabilidade.

No que diz respeito a procedimentos diagnósticos, a constante atualização e renovação do conhecimento exige que o especialista esteja permanentemente informado e reciclando seus conhecimentos. No entanto é importante enfatizar que muitos processos diagnósticos são comuns a várias áreas do conhecimento médico, muitas vezes sendo melhor praticado por profissionais que se dedicam exclusivamente a isso.

O conhecimento é dinâmico e por isso mesmo mutável, não haverá um trabalho que por si só encerre o assunto. Controvérsias, polêmicas e maiores estudos são necessários para o constante crescimento da especialidade e para a necessária atualização do especialista.

Por último vale ressaltar: A elegância, a ética e a competência, devem preponderar na relação médico-médico e médico-paciente.

A elegância de saber e poder encaminhar o paciente para procedimentos que fogem à sua formação, garantindo-se que é ético e oportuno a solicitação de novos procedimentos naquele momento, garantindo-se ainda que o encaminhamento está calcado na real necessidade do paciente e não na "generosa" atitude de favorecer o colega, com a competência de reconhecer sua própria limitação e de permitir ao paciente uma melhor oportunidade diagnóstica e terapêutica.

\section{Referências Bibliográficas}

1. DELISE, J.A; GORDON M.M. - Rehabilitation Medicine Past Present and Future in Rehabilitation Medicine: Principle and practice. Edited by Joel a Delise. J.B. Lippincott, Philadelphia, 1988.

2. fRAGA FILHO, C. et al: - Ensino de Clínica Médica. Rev. Ass. Med. Brasil 39(4) 198-200. 1993.

3. KOTKKE F.J.: Future Focus of Rehabilitation Medicine: Arch Phy Med Rehab 61:1-6. 1980. 